\title{
Aprendizagem da compreensão leitora: uma proposta de transposição didática da Teoria da Polifonia e da Teoria dos Blocos Semânticos
}

\author{
Apprentissage de la compréhension en lecture: proposition de transposition \\ didactique de la Théorie de la Polyphonie et de la \\ Théorie des Blocs Sémantiques
}

\section{Tânia Maris de Azevedo}

Universidade de Caxias do Sul - UCS - Caxias do Sul - Rio Grande do Sul - Brasil

\begin{abstract}
$\longrightarrow$
Resumo: Neste artigo trago à discussão uma proposta de ensino da compreensão leitora fundada na Teoria da Argumentação na Língua (TAL), de Oswald Ducrot e Marion Carel. Concebendo a compreensão leitora como uma habilidade a ser constantemente desenvolvida pelo sujeito leitor, penso que a transposição didática da Teoria da Polifonia e da Teoria dos Blocos Semânticos, versões mais recentes da TAL, pode contribuir significativamente para a aprendizagem ou a qualificação da leitura. A ideia que submeto aqui à apreciação da comunidade científica é a de que, por um lado, a concepção polifônica do sentido é capaz de subsidiar o desenvolvimento do nível analítico da compreensão em leitura. Por outro lado, a Teoria dos Blocos Semânticos fornece mecanismos que, devidamente transpostos para o contexto de aprendizagem, potencializam, in thesis, o desenvolvimento do nível sintético da compreensão leitora.
\end{abstract}

Palavras-chave: Ensino e aprendizagem de leitura. Compreensão leitora. Teoria da Polifonia. Teoria dos Blocos Semânticos. Transposição didática.

Résumé: Dans cet article je mets en discussion une proposition d'enseignement de la compréhension en lecture fondée sur la Théorie de l'Argumentation dans la Langue (ADL), d'Oswald Ducrot et Marion Carel. En concevant la compréhension en lecture comme une capacité à être développée en permanence par le sujet lecteur, je pense que la transposition didactique de la Théorie de la Polyphonie et de la Théorie des Blocs Sémantiques, les versions les plus récentes de l'ADL, peut contribuer de manière significative à l'apprentissage ou à la qualification de la lecture. L'idée que je présente ici à l'appréciation de la communauté scientifique est celle que, d'une part, la conception polyphonique du sens est capable de soutenir le développement du niveau analytique de la compréhension en lecture. D'autre part, la Théorie des Blocs Sémantiques fournit les mécanismes qui, bien transposés pour un contexte d'apprentissage, favorisent, in thesis, le développement du niveau synthétique de la compréhension en lecture.

Mots-clés: Enseignement et apprentissage de la lecture. Compréhension en lecture. Théorie de la Polyphonie. Théorie des Blocs Sémantiques. Transposition didactique. 


\section{Introdução}

O processo de leitura e as habilidades por ele pressupostas constituem-se objeto de estudo de muitas investigações em diversas áreas do conhecimento científico e filosófico. Vários são os vieses sobre os quais a leitura tem sido pesquisada, desde, pelo menos, a Linguística, a Pedagogia, a Filosofia, a Sociologia, a Antropologia, e, para não nomear apenas os estudos das Humanidades, também desde, por exemplo, a Ciência Jurídica. No que diz respeito à Linguística, a leitura tem sido examinada, minimamente, pela Psicolinguística, Linguística do Texto, Análise do Discurso, Semântica.

Bem, basta de enumerações para dizer que poucos são, ainda, os estudos enunciativos do processo de ler e, menos ainda, da aprendizagem e, consequentemente, do ensino - da leitura. Essa asserção pode impactar o leitor deste artigo, mas, se digo isso, o faço pelo fato de que, pelas várias buscas realizadas, não encontrei a explicitação de uma concepção de leitura como processo enunciativo, especialmente aquela vinculada aos pressupostos saussurianos e ducrotianos.

O preocupante contexto atual brasileiro referente ao desempenho discente em leitura atestado por respeitáveis processos avaliativos como Prova Brasil, Exame Nacional do Ensino Médio (ENEM), Exame Nacional de Desempenho de Estudantes (ENADE), Programa Internacional de Avaliação de Alunos (PISA) -, o qual dispensa maior detalhamento dada sua extensa divulgação, desafia a comunidade científica a vislumbrar, buscar e/ou urdir, constantemente, outros pontos de vista sobre o processo de aprendizagem da leitura $e$, mais especificamente neste caso, sobre o desenvolvimento da compreensão leitora, uma das habilidades mais comprometidas segundo as avaliações feitas.

Nesse quadro se inscreve (e, quiçá, se justifique) 0 presente estudo, que figura, neste momento, como uma grande conjectura de natureza essencialmente teórica. Destarte, lanço à discussão uma proposta de transposição didático-pedagógica da
Teoria da Argumentação na Língua ${ }^{1}(T A L)$, de Oswald Ducrot e Marion Carel - nomeadamente, a Teoria da Polifonia (TP) e a Teoria dos Blocos Semânticos (TBS) -, ao ensino da compreensão leitora.

Sigamos, então, rumo ao alcance desse intento.

\section{Alguns esclarecimentos conceituais}

Antes de iniciar propriamente a discussão objeto deste artigo, parece-me necessário, caro leitor, examinarmos, um pouco mais detidamente, alguns dos conceitos mencionados acima.

Em primeiro lugar, quando refiro leitura, restrinjo-me aqui à leitura do discurso ${ }^{2}$ escrito e a concebo, consoante Azevedo (2016), como um processo enunciativamente interativo do leitor com o discurso, a fim de (re)constituir o sentido do que está sendo lido por meio da compreensão e da interpretação desse discurso.

Em segundo lugar, se circunscrevo a proposta deste trabalho à compreensão leitora, é porque, como já explicitei em, por exemplo, Azevedo (2016), entendo leitura como um processo que pressupõe o desenvolvimento das habilidades ${ }^{3}$ implicadas na decodificação, na compreensão e na interpretação.

Isso requer uma explicação um pouco mais detalhada, já que o segundo conjunto de habilidades - aquele relativo à compreensão - é o objeto deste estudo e, por concernir ao aspecto estritamente linguístico do discurso, é o recorte metodológico

\footnotetext{
1 Também referida, ao longo deste texto, como Semântica Linguística e/ou Semântica Argumentativa.

2 Mais adiante, explico a razão de, seguindo os constructos ducrotianos, utilizar discurso e não texto.

${ }^{3}$ Habilidade, neste estudo, é concebida como um saberfazer, logo, precisa ser desenvolvido e qualificado constantemente e pressupõe uma situação aqui/agora em que a prática seja efetivada. Dito isso, torna-se inócuo pensar em, por exemplo, planejar aulas essencialmente teóricas para que uma habilidade seja desenvolvida. Aplicando esse princípio mais diretamente ao ensino de língua: aulas de estudo da gramática normativa e atividades de pura classificação morfológica e/ou sintática parecem ineficazes para 0 desenvolvimento das habilidades que as práticas discursivas (leitura e produção) exigem. Para maiores esclarecimentos sobre esse tema ver, por exemplo, Falkenbach \& Azevedo (2018), Azevedo (2016) e Azevedo e Rowell (2009).
} 
sobre o qual a Teoria da Argumentação na Língua se debruça, me permitindo, desse modo, lançar aqui a conjectura essencial a que me proponho. Importante também se faz esclarecer que as concepções a seguir têm sua validade restrita ao âmbito deste artigo.

Por decodificação entendo o processo de decifração do código escrito, desde o reconhecimento do alfabeto utilizado até um nível primário de compreensão desse uso. Compreensão aqui é vista como a assimilação, por meio de análise, das interconexões das palavras em cada enunciado e dos enunciados entre si, de um lado, e, de outro, pela síntese de tais inter-relações para a constituição do sentido do discurso como totalidade semântica. Portanto, o que proponho é que a compreensão seja subdividida complementarmente em compreensão analítica e compreensão sintética ${ }^{4}$. Por óbvio, a compreensão tem como pré-requisito necessário a decodificação.

Vejo 0 terceiro grupo de habilidades pressupostas pela leitura, denominado interpretação, como o mais complexo, pois, além de requerer a decodificação e a compreensão, exige que o leitor relacione o conteúdo temático do discurso com os contextos em que foi produzido e em que está sendo lido, isto é, com a situação enunciativa que lhe deu origem e com aquela em que o leitor está a cada vez que o lê.

Pensando assim, creio que posso falar em leitura numa perspectiva enunciativo-discursiva. Como bem diz, Teixeira (2005, p. 199),

O sentido não é dado imediatamente pelo texto, mas produzido ativamente por aquele que lê, no "aqui e agora" em que se dá a leitura, momento que é sempre outro, e que faz com que o mesmo leitor produza sempre novos sentidos. Tal perspectiva implica reconhecer que há algo de subjetivo na recepção. (TEIXEIRA, 2005, p. 199).
Na própria Base Nacional Comum Curricular para o Ensino Fundamental e Médio (BNCC), a abordagem eleita para o ensino de língua, materna e estrangeira, parece ser a mesma que alicerça o que ora proponho. Na BNCC, é dito explicitamente que o discurso ("texto" como é referido no documento) constitui o ponto central da dinâmica pedagógica e tem no aporte enunciativo-discursivo seu principal pressuposto teórico e metodológico.

Tal proposta assume a centralidade do texto como unidade de trabalho e as perspectivas enunciativo-discursivas na abordagem, de forma a sempre relacionar os textos a seus contextos de produção e o desenvolvimento de habilidades ao uso significativo da linguagem em atividades de leitura, escuta e produção de textos em várias mídias e semioses. (BRASIL, 2018, p. 65).

Além disso, a BNCC apresenta um elenco de práticas de leitura que, consoante o documento, "compreende dimensões inter-relacionadas às práticas de uso e reflexão" (BRASIL, 2018, p. 71). Para referendar o que trago aqui como proposição, que tem por fim potencializar o desenvolvimento da habilidade de compreensão leitora, reproduzo um fragmento de um dos quadros que elenca essas "práticas de uso e reflexão".

\begin{tabular}{|c|c|}
\hline $\begin{array}{l}\text { Reconstrução } \\
\text { textualidade, } \\
\text { recuperação e análise } \\
\text { da organização } \\
\text { textual, da progressão } \\
\text { temática e } \\
\text { estabelecimento de } \\
\text { relações entre as } \\
\text { partes do texto }\end{array}$ & $\begin{array}{l}\text { Estabelecer relações entre } \\
\text { as partes do texto, } \\
\text { identificando repetições, } \\
\text { substituições e os elementos } \\
\text { coesivos que contribuem para } \\
\text { a continuidade do texto e sua } \\
\text { progressão temática. } \\
\text { Estabelecer relações lógico- } \\
\text { discursivas variadas } \\
\text { (identificar/ distinguir e } \\
\text { relacionar fato e opinião; } \\
\text { causa/efeito; tese/ argumentos; } \\
\text { problema/solução; } \\
\text { definição/exemplos etc.). } \\
\text { - Selecionar e hierarquizar } \\
\text { informações, tendo em vista as } \\
\text { condições de produção e } \\
\text { recepção dos textos. }\end{array}$ \\
\hline
\end{tabular}

\footnotetext{
${ }^{4}$ Para o leitor mais afoito, é justamente essa subdivisão que me permite propor a Teoria da Polifonia e a Teoria dos Blocos Semânticos como referenciais para a potencialização do desenvolvimento da habilidade de compreensão leitora.
} 


\begin{tabular}{|c|c|}
\hline \multirow{4}{*}{$\begin{array}{lr}\text { Compreensão } & \text { dos } \\
\text { efeitos de } & \text { sentido } \\
\text { provocados } & \text { pelos } \\
\text { usos de recursos }\end{array}$} & \\
\hline & implícitos e os efeitos \\
\hline & sentido decorrentes \\
\hline & determinados usos \\
\hline $\begin{array}{l}\text { linguísticos } \\
\text { multissemióticos em } \\
\text { textos pertencentes a } \\
\text { gêneros diversos }\end{array}$ & $\begin{array}{l}\text { expressivos da linguagem, } \\
\text { da pontuação e de outras } \\
\text { notações, da escolha de } \\
\text { determinadas palavras ou } \\
\text { expressões e identificar } \\
\text { efeitos de ironia ou humor. }\end{array}$ \\
\hline
\end{tabular}

Fonte: BRASIL, 2018, p. 71.

O documento não explicita se há uma ordem nessa sequência em que o quadro é organizado e, sinceramente, espero que não haja, pois me parece que o segundo tópico diz respeito ao que chamo compreensão analítica e o primeiro, à compreensão sintética; não vejo como sintetizar o que ainda não foi devidamente analisado, uma vez que esses são processos cognitivos cuja sequência não é nem optativa, nem recursiva.

Afora o comentário anterior, fica claro nesses tópicos previstos na BNCC que a compreensão leitora é fundamental e precisa ser objeto de aprendizagem em todos os anos da Educação Básica. Igualmente, ficam explicitados os dois tipos/níveis (analítico e sintético) que proponho para o desenvolvimento do grupo de habilidades que a compreensão leitora pressupõe.

Por exemplo, no que diz respeito à compreensão leitora analítica, a BNCC explicita no segundo tópico à direita no quadro acima: "Identificar implícitos e os efeitos de sentido decorrentes de determinados usos expressivos da linguagem, da pontuação e de outras notações, da escolha de determinadas palavras ou expressões e identificar efeitos de ironia ou humor." Não creio que a mera identificação de implícitos e de "efeitos de sentido" possa ser suficiente para oportunizar 0 desenvolvimento, pelo aprendiz, da habilidade de compreensão, mas, talvez, o entendimento do que está pressuposto e em quê esses usos de língua contribuem para a constituição do sentido do discurso em sua totalidade. Nessa direção, e para potencializar a compreensão analítica, eu acrescentaria o reconhecimento das relações de sentido intraenunciados - entre palavras, por exemplo - e interenunciados - como a articulação e a conexão.

Já, no que tange ao que chamo compreensão sintética, o mesmo quadro traz: "Estabelecer relações entre as partes do texto, identificando repetições, substituições e os elementos coesivos que contribuem para a continuidade do texto e sua progressão temática.". Por óbvio esses tópicos não estão dispostos no quadro segundo o que eu denomino compreensão analítica e sintética, há uma mescla entre esses dois "níveis" de compreensão. Nesse item, que elementos indicam tratar-se da compreensão sintética? Creio que se possa ver esse processo de compreensão nas seguintes referências: o estabelecimento de "relações entre as partes do texto", a identificação de "repetições e substituições" e de outros "elementos coesivos que contribuem para a continuidade do texto e sua progressão temática". Torna-se possível perceber aí uma espécie de reconstrução do sentido do discurso após a decomposição feita via compreensão analítica.

Faz-se necessário aqui um parênteses para dizer que o leitor proficiente realiza análise e a síntese quase simultaneamente ao ler um discurso, no entanto, o mais comum é que cada um desses processos seja efetivado em um movimento de leitura, ou seja, uma primeira leitura em que o leitor empreende a compreensão analítica e uma segunda, em que efetua a sintética; tanto é assim que alguns manuais que versam sobre estratégias de leitura, e mesmo de redução de informação, recomendam duas leituras de um mesmo discurso a fim de compreendêlo.

Voltando ao tópico em questão, novamente penso que a mera identificação dos elementos que viabilizam a trama discursiva não é suficiente para a reconstituição da unidade semântica; é imprescindível à compreensão sintética a reconstrução dessa urdidura de sentido que é o discurso, isto é, a compreensão de como foram utilizados os elementos linguísticos na produção do discurso para construir essa teia de sentido. Como bem o dizem Teixeira e Ferreira (2008, p. 68), é fundamental que se auxilie o aprendiz "a observar o modo como as palavras circulam pelo enunciado, inter-relacionando-se com 
outras para a expressão da idéia do enunciador.".

Caro leitor, agradeço-lhe por ter me acompanhado até aqui e espero ter ficado clara minha concepção semântico-enunciativa de leitura, ou mais especificamente, de compreensão leitora. É chegada a hora de apresentar, a título de conjectura, a proposta de transposição didática da Teoria da Polifonia, de Oswald Ducrot, e da Teoria dos Blocos Semânticos, de Marion Carel e Oswald Ducrot, como potencializadoras do desenvolvimento da habilidade de compreensão leitora pelos aprendizes de uma dada língua.

\section{Vozes imbricadas na compreensão leitora}

Não vou fazer aqui uma retrospectiva da Teoria da Polifonia de Oswald Ducrot, pois, além dos limites próprios de um artigo como este, ao leitor interessado em aprofundar estudos nesta Teoria seguem, dentre outras, as referências ao final deste texto. $\mathrm{O}$ mesmo vale para o aporte teórico referente à transposição didática ${ }^{5}$. Prefiro passar diretamente à proposta que lanço à discussão.

Como defini anteriormente, o processo de compreensão leitora pode ser dividido em duas etapas: compreensão analítica e sintética. Sabe-se muito bem que compreender um discurso escrito exige entender o que está dito, explícita e/ou implicitamente. Pois bem, a proposta que pretendo demonstrar aqui é a de que a transposição didática da Teoria da Polifonia (TP) pode contribuir significativamente para a potencialização e otimização do processo de compreensão leitora analítica pelos estudantes, sejam eles de que nível forem, pois, como habilidade que é, a compreensão pode ser desenvolvida ao longo de toda a instrução formal.

Para esse empreendimento usarei a versão da TP apresentada por Ducrot em O dizer e o dito (1987) e nas conferências realizadas em Cali, na Colômbia, publicadas em 1990, uma vez que, para o propósito que tenho aqui, essa versão da TP se adequa bem e,

\footnotetext{
${ }^{5}$ Como, por exemplo, Chevallard (1991), Álvarez (2005), Revue Pratiques (n॰97-98, 1998) e Azevedo (2016a).
}

por outro lado, porque a versão mais atual está ainda em elaboração. Bem, vamos a ela.

Ducrot (1987) formula sua Teoria da Polifonia, contrapondo-se à concepção mais em voga na época, a de que um único sujeito (o autor) é o responsável pelo que é dito em enunciados ${ }^{6}$ e discursos. Para o semanticista (1987, p. 163), "Não se trata mais do que se faz quando se fala, mas do que se considera que a fala, segundo o próprio enunciado, faz.”. E continua dizendo que "todo enunciado traz consigo uma qualificação de sua enunciação, qualificação que constitui para mim o sentido do enunciado." (1987, p. 163-164).

Ainda no mesmo texto Ducrot (1987, p. 172) explicita sua concepção de sentido como "uma descrição da enunciação" e afirma que o objetivo de uma concepção polifônica do sentido é "mostrar como o enunciado assinala, em sua enunciação, a superposição de diversas vozes".

Quais são essas vozes? A primeira, não em ordem de importância ou hierárquica, é a do "sujeito empírico" (SE) (DUCROT, 1987, passim; DUCROT, 1990, p. 16-17), ou seja, a pessoa física que produz o enunciado ou o discurso e cuja determinação não é, segundo o semanticista parisiense,

un problema lingüístico. El lingüista y en particular el lingüista semanticista debe preocuparse por el sentido del enunciado, es decir debe describir lo que dice el enunciado, lo que éste aporta. De manera que lo que interesa es lo que está en el enunciado y no las condiciones externas de su producción. El problema (importante) de la determinación del SE es más bien perocupación de los sociolingüistas o los sicolingüistas, que se formulan preguntas como ¿por qué el señor $X$ dijo lo que dijo? Lo que a mí me interesa es sencillamente lo que dijo el señor $X$. (DUCROT, 1990, p. 17 - grifos do autor).

\footnotetext{
${ }^{6}$ Cabe aqui um esclarecimento. Ducrot (1984) define enunciado como a realização linguística da entidade abstrata, logo inscrita no sistema linguístico, denominada frase. Portanto, como diz o autor, só podemos ouvir e ver enunciados, não frases. Além disso e por decorrência, na mesma obra, Ducrot designa discurso como entidade linguística concreta (equivalente complexa da entidade simples enunciado) que, por uma trama semântica de enunciados realiza, materializa, manifesta o texto, que, analogamente a frase, é a entidade abstrata só que de nível complexo.
} 
A segunda voz é, consoante Ducrot, a do locutor, entendido como um ser discursivo designado, por um enunciado/discurso, como responsável pelo conteúdo semântico dessas manifestações linguísticas e que nelas aparece marcado, por exemplo, com o uso de expressões em primeira pessoa.

llustremos com um discurso essas duas primeiras vozes. Acima de uma lixeira para lixo reciclável vê-se uma placa na qual está escrito o discurso $\mathrm{D}(1)$ :

$\mathrm{D}(1)$ - Por favor, não ponha lixo orgânico em mim.

Quem produziu D(1)? Quem é o "mim” em $\mathrm{D}(1)$ ? O sujeito empírico e o locutor coincidem? A resposta a esta última pergunta é não, pois o produtor de $\mathrm{D}(1)$ é, por exemplo, quem confeccionou a placa, mas o locutor é a lixeira, identificada pelo pronome "mim" e responsável pelo pedido feito.

Entretanto, Ducrot (1987, p. 191-192) apresenta uma terceira função discursiva capaz de evidenciar ainda mais sua proposta polifônica: a função enunciador. Declara o autor:

Chamo "enunciadores" estes seres que são considerados como se expressando através da enunciação, sem que para tanto se the atribuam palavras precisas: se eles "falam" é somente no sentido em que a enunciação é vista como expressando seu ponto de vista, sua posição, sua atitude, mas não, no sentido material do termo, suas palavras. (DUCROT, 1987 , p. 192 - grifos do autor).

Em 1988, nas conferências que realizou na Colômbia, Ducrot altera um pouquinho a definição de enunciador, esclarecendo que os enunciadores são, na verdade, as origens dos vários pontos de vista expressos pelo enunciado/discurso e em relação às quais o locutor adota algumas atitudes. De acordo com Ducrot (1990, p. 19-20),

todo enunciado presenta un cierto número de puntos de vista relativos a las situaciones de las que se habla [...]. Describir el sentido de un enunciado consiste, a mi juicio, entre otras cosas, en responder a diversas preguntas: $i$ el enunciado contiene la función locutor?, ¿a quién se le atribuye esta función?, ¿a quién se asimila el locutor?, ¿cuáles son los diferentes puntos de vista expresados, es decir cuáles son las diferentes funciones de enunciador presentes en el enunciado?, ¿a quién se atribuyen eventualmente estas funciones?

Voltando a $\mathrm{D}(1)$,

D(1) - Por favor, não ponha lixo orgânico em mim.

podemos ver aí alguns enunciadores (e), tais como:

$$
\begin{aligned}
& \mathrm{e}_{1} \text { : não pôr lixo orgânico em mim é um favor } \\
& \mathrm{e}_{2} \text { : pôr lixo orgânico em mim é um favor } \\
& \mathrm{e}_{3} \text { : não ponha lixo orgânico em mim } \\
& \mathrm{e}_{4} \text { : ponha lixo orgânico em mim }
\end{aligned}
$$

Em $\mathrm{D}(1)$, os enunciadores $e_{1}$ e $e_{2}$ são pontos de vista que explicitam a gentileza solicitada, ao passo que $e_{3}$ e $e_{4}$ pôem à mostra a ordem dada sem a modalização expressa em "Por favor". Por outro lado, cabe explicar que $e_{2}$ e $e_{4}$ são, segundo Ducrot (1987 e 1990), os enunciadores pressupostos pela negação presente em $\mathrm{e}_{1} \mathrm{e} \mathrm{e}_{3}$.

Se o leitor bem lembra, um pouco mais acima falei em atitudes que o locutor $(L)$ adota em relação a cada enunciador, ou seja, como se posiciona o locutor de um enunciado ou discurso diante de cada ponto de vista atualizado por ele. Além disso, na última fala de Ducrot que eu trouxe aqui, o semanticista questiona, a fim de descrever o sentido de uma entidade linguística concreta (enunciado ou discurso), a quem se assimila o locutor, isto é, qual o ponto de vista assumido por $L$ no enunciado/discurso cujo sentido está sendo descrito.

Pois bem, três são as atitudes que o locutor pode ter com relação a cada enunciador realizado em seu enunciado/discurso. Ducrot (1990, p. 66-67) estabelece que as três atitudes são: (a) L identifica-se com um enunciador no sentido de assumir o ponto de vista por este veiculado; (b) L aprova o conteúdo semântico revelado por um enunciador, concordando com ele mesmo que o enunciado não objetive fazer admitir esse conteúdo; e (c) L pode opor-se a um dos pontos de vista presentes no enunciado/discurso, recusando ou rejeitando esse enunciador.

Em D(1), tem-se como atitudes de $L$ no que 
concerne a cada enunciador por ele atualizados as de:

(a) aceitar $\mathrm{e}_{1}$ e $\mathrm{e}_{2}$

$\mathrm{e}_{1}$ : não pôr lixo orgânico em mim é um favor

$\mathrm{e}_{2}$ : pôr lixo orgânico em mim é um favor,

(b) recusar $\mathrm{e}_{4}$

$\mathrm{e}_{4}$ : ponha lixo orgânico em mim

(c) assumir $\mathrm{e}_{3}$

$\mathrm{e}_{3}$ : não ponha lixo orgânico em mim.

Justamente pelo fato de a Teoria da Polifonia pôr à mostra tudo o que é dito ao dizer é que proponho sua transposição didática para otimizar o desenvolvimento da habilidade de compreender analiticamente um discurso escrito. É comum ouvirmos professores comentando que seus alunos só entendem o que está explícito ou nem isso, portanto, uma Teoria que pela descrição semântica que propõe desnuda todos os pontos de vista mobilizados pelo locutor para a constituição do sentido dos enunciados/discursos parece ter potencial de contribuir para a qualificação da compreensão leitora analítica como foi definida aqui.

Suponhamos, a título de exemplo, que o discurso $D(1)$ fosse objeto de uma atividade de compreensão leitora analítica para alunos do Ensino Fundamental. Que questões poderiam ser formuladas de modo a fazê-los perceber os vários pontos de vista atualizados pelo locutor nesse discurso?

$$
\begin{aligned}
& D(1) \text { - Por favor, não ponha lixo orgânico em } \\
& \text { mim. }
\end{aligned}
$$

Uma primeira questão para que o leitor identifique o locutor de $\mathrm{D}(1)$ poderia ser algo como: quem é o "mim" em "não ponha lixo orgânico em mim"?. E perguntas para a compreensão dos pontos de vista dos enunciadores poderiam ser: (a) $O$ que $O$ uso da expressão "Por favor" evidencia em relação à postura da lixeira?; (b) $E$ se a lixeira não tivesse utilizado a expressão "Por favor", o que ela diz ainda poderia ser considerado um pedido? (c) Por que a lixeira precisa dizer o que diz em $D(1)$ ?

Por óbvio, para que o professor pudesse elaborar questões como essas seria necessário a ele compreender a Teoria da Polifonia de Ducrot. No entanto, por não ser um pesquisador semanticista ${ }^{7}$, não precisaria de um conhecimento aprofundado sobre ela, sendo que o estudo da TP poderia ser objeto de uma disciplina na licenciatura em Letras ou de uma atividade de formação continuada. Penso do mesmo modo em relação à Teoria dos Blocos Semânticos (TBS), de Carel e Ducrot, a qual passo a apresentar tão resumidamente quanto o necessário para finalizar esta proposta de transposição didática para o ensino da compreensão leitora, agora a compreensão sintética.

Antes disso, torna-se importante salientar que a transposição didática da Teoria da Argumentação na Língua para professores tem sido objeto de minhas investigações e está no centro da pesquisa que desenvolvo atualmente, com apoio do CNPq, intitulada Transposição didática da Teoria dos Blocos Semânticos para o ensino da compreensão leitora na Educação Básica.

\section{Blocos de sentido pressupostos pela compreensão leitora}

Da mesma forma que fiz com a Teoria da Polifonia farei com a Teoria dos Blocos Semânticos (TBS), não entrarei nos meandros da evolução da Teoria nem em todo o seu detalhamento ${ }^{8}$, tratarei apenas do estritamente essencial para demonstrar a proposta que trago aqui.

Ducrot (2005a), como já o fez em outros textos, reitera a posição radicalmente estruturalista de sua Teoria da Argumentação na Língua (TAL), da qual a TBS faz parte. Nesse sentido, afirma (2005a, p. 11-12) que a TAL partiu da noção saussuriana de valor, a qual deriva, consoante o semanticista, da concepção de Saussure sobre o significado, dizendo,

\footnotetext{
7 Proponho uma distinção entre o linguista, o usuário de língua e o professor de língua em Azevedo (2016b).

${ }^{8}$ Quem estiver interessado em aprofundar o estudo da TBS pode ver, por exemplo, Carel e Ducrot (2005), Ducrot e Carel (2008), Ducrot (2009), Carel (1997, 1998, 2005), Azevedo (2006, 2007, 2015).
} 
este, que o significado de um signo se constitui pela relação que mantém com todos os outros signos do sistema linguístico. Além disso, continua Ducrot, para Saussure o significado de um signo não tem nenhuma referência externa ao sistema de que faz parte, não se forma por ideias ou conceitos, mas única e exclusivamente pelas relações com os outros signos de uma dada língua.

Pois bem, Ducrot (2005a, p. 11-12 - grifos do autor) analisa essa ideia de relação de um signo com todos os outros de um mesmo sistema linguístico como "relativamente vaga" e propõe, por meio da $\mathrm{TAL}$, "considerar como relações semanticamente pertinentes as argumentativas, quer dizer, os encadeamentos argumentativos em portanto [donc (DC), em francês] entre um signo e outro" . Dessa inscrição no sistema linguístico das relações argumentativas definidoras do significado de um signo advém a própria denominação da teoria ducrotiana como Teoria da Argumentação na Língua ou como também é chamada Semântica Argumentativa. Carel (2017, p. 05) explica essa designação apresentando a hipótese de base da Teoria: "A argumentação está na língua no sentido de que a significação fora de emprego contém diretamente indicações sobre as argumentações que poderão ser desenvolvidas no discurso quando do emprego das palavras.".

A proposta da TBS por Marion Carel agrega aos encadeamentos em donc (DC) aqueles em pourtant (PT). Encadeamento argumentativo é definido por Carel (2017) como, em última análise, a realização de um bloco semântico, este como uma entidade inscrita no sistema linguístico constituído de uma união indissolúvel entre dois conceitos e resultante da interdependência semântica desses conceitos. Como explica Carel (2017, p. 06),

Todo enunciado é parafraseável por encadeamentos que comportam uma conjunção do tipo donc (se, porque, pois,...) ou uma conjunção do tipo pourtant (no entanto, ainda que, mesmo se,...), e a significação das palavras, associada à sintaxe e à estrutura do texto, permite prever essas paráfrases.

Acresça-se a essa descrição de encadeamento argumentativo o indicador de negação -neg.
Voltemos ao nosso exemplo. O discurso D(1),

$\mathrm{D}(1)$ - Por favor, não ponha lixo orgânico em $\operatorname{mim}$,

só pôde ser produzido, porque a língua contém um encadeamento argumentativo como lixo orgânico DC-neg pôr em mim e, sabendo-se pela indicação da enunciação de que se trata de uma placa aposta acima de uma lixeira e de que, por isso, o locutor $L$, expresso pelo mim em $\mathrm{D}(1)$, é uma lixeira para lixo reciclável, o bloco semântico concretizado por esse encadeamento pode ser formulado como lixo orgânico-lixo reciclável.

Então, dando sequência à proposta de transposição didática, creio que a Teoria dos Blocos Semânticos pode contribuir significativamente para o desenvolvimento da compreensão leitora sintética, pois possibilita pôr em evidência os encadeamentos responsáveis pela constituição do sentido de enunciados e discursos de uma língua. Como ilustração dessa ideia, ainda considerando o discurso $D(1)$, penso ser possível verificar se o leitor compreendeu a síntese desse discurso por meio de uma questão como

Do ponto de vista da fala da lixeira, é correto afirmar que:

( ) o lixo reciclável precisa ser colocado em outro recipiente.

( ) ela pede o favor de não depositar nenhum lixo nela.

( ) nela só deve ser colocado o lixo orgânico.

( ) o favor solicitado por ela não condiz com sua função.

Acredito que a resposta correta de uma questão como esta demande que o leitor tenha compreendido analiticamente $\mathrm{D}(1)$ e, posteriormente (dada a hierarquia desses níveis de compreensão leitora, abordada no início deste trabalho), identifique - encadeamento argumentativo que sintetiza o conteúdo semântico do discurso.

Obviamente, e é isso que venho investigando, a proposta apresentada precisa ser devidamente validada, mas, conforme disse anteriormente, o 
objetivo deste artigo é o de divulgar tal conjectura junto à comunidade científica.

\section{Algumas palavras finais}

Neste artigo, tive a pretensão (em todos os sentidos) de expor uma grande hipótese: a de que a Teoria da Polifonia e a Teoria dos Blocos Semânticos - integrantes da Teoria da Argumentação na Língua, de Oswald Ducrot e Marion Carel - podem auxiliar os estudantes da Educação Básica e Superior a potencializarem e otimizarem o desenvolvimento das habilidades de compreensão leitora analítica e sintética.

Procurei, mesmo que breve e superficialmente, demonstrar a viabilidade de transpor didaticamente elementos estruturantes dessas teorias para o ensino da compreensão leitora. Se digo isso, é pelo fato de ter consciência de que qualquer estudo que aspire cientificidade precisa ser devidamente aprofundado e ter testadas suas proposições. É justamente nessa direção que minhas pesquisas têm me guiado e espero em um tempo não muito longo poder divulgar mais do que apenas uma conjectura.

Se estendo a hipótese explanada aqui a todo e qualquer nível de ensino, é por julgar que habilidades como as pressupostas pela compreensão leitora são objeto de desenvolvimento, no mínimo, durante todo o processo de instrução formal, no sentido de poderem ser sempre mais qualificadas, aprimoradas. E mais: o que propus neste trabalho deve poder ser aplicado à leitura de todas as tipologias textuais e de seja qual for o gênero discursivo, pois, consoante a hipótese fundante da TAL, a argumentação constitui a significação de todas as entidades produzíveis por uma língua, uma vez que está inscrita no próprio sistema linguístico.

Por fim, acredito firmemente que formar um leitor proficiente seja um dos grandes objetivos de todos os professores, e isso passa, certamente, pela verdadeira compreensão do sentido constituído nos e pelos discursos de uma determinada língua.

\section{Referências}

ÁLVAREZ, Teodoro. Didáctica del texto en la formación del professorado. Madrid: Síntesis, 2005.

AZEVEDO, Tânia Maris de. Em busca do sentido do discurso: a semântica argumentativa como uma possibilidade para a descrição do sentido do discurso. Caxias do Sul: Educs, 2006.

AZEVEDO, Tânia Maris de. Discurso didático: um modelo para descrição do sentido pela semântica argumentativa. In Conjectura, v. 16, n. 2, maio./ago. 2011, p. 39-55.

AZEVEDO, Tânia Maris de. Gradualidade , uma constante na Semântica Argumentativa. In Estudos da Língua(gem), 13, n. 1, junho 2015, p. 81-96.

AZEVEDO, T. M.. Polifonia linguística: uma proposta de transposição didática para o ensino da leitura. Letras de Hoje, v. 51, 2016a, p. 73-81.

AZEVEDO, T. M.. Encadeamentos argumentativos, relações sintagmáticas e associativas: reflexões sobre o ensino da leitura. In ANTARES, vol. 8, n15 - Jan/.jun. 2016b, p. 48-65.

AZEVEDO, T. M.; ROWELL, Vania Morales . Problematização e ensino de língua materna. Pesquisas em Discurso Pedagógico, v. 1, p. 1-21, 2009.

CAREL, M.; DUCROT, O. La semántica argumentativa: una introducción a la teoria de los bloques semánticos. Buenos Aires: Colihue, 2005.

CAREL, Marion. Argumentación normativa y argumentación exceptiva. In Signo y Seña, n. 9, jun. 1998, p. 257-298.

CAREL, Marion. L'argumentation dans le discours: argumenter n'est pas justifier. Letras de Hoje, Porto Alegre, v. 32, n. 1, mar. 1997, p. 23-40.

CAREL, Marion. Significação e argumentação. In Signo. Santa Cruz do Sul, v. 42, n. 73, p. 02-20, jan./abril 2017, p. 02-20.

CHEVALLARD, Yves. La transposición didáctica: del saber sabio al saber enseñado. Buenos Aires: Aique, 1991

DUCROT, Oswald. Enunciação. In: Enciclopédia EINAUDI. Vol. 2: Linguagem - Enunciação. Lisboa, Imprensa Nacional - Casa da Moeda, 1984, p. 368-393.

DUCROT, Oswald. O dizer e o dito. Campinas, SP: Pontes, 1987.

DUCROT, Oswald. Polifonía y argumentación conferencias del seminario Teoría de la 
Argumentación y Análisis del Discurso. Cali, Universidad del Valle, 1990.

DUCROT, Oswald. Introducción: conferencia 1. In CAREL, M.; DUCROT, O. La semántica argumentativa: una introducción a la teoria de los bloques semánticos. Buenos Aires: Colihue, 2005a, p. 09-25.

DUCROT, Oswald. Los bloques semânticos y el cuadrado argumentativo: conferencia 2 . In CAREL, M.; DUCROT, O. La semántica argumentativa: una introducción a la teoria de los bloques semánticos. Buenos Aires: Colihue, 2005b, p. 27-50.

DUCROT, Oswald. Argumentação retórica e argumentação linguística. In Letras de Hoje, Porto Alegre, v. 44, n. 1, p. 20-25, jan./mar. 2009, p. 2025.

FALKENBACH, L.I.S. \& AZEVEDO, T.M. A Teoria da Argumentação na Língua no ensino de compreensão leitora. Letrônica, Porto Alegre, v. 11, n. 2, p. 169-180, 2018.

TEIXEIRA, Marlene e FERREIRA, Sabrina. Leitura na escola: um barco à deriva? Letras de Hoje, Porto Alegre, v. 43, n. 1, p. 63-68, 2008.

TEIXEIRA, Marlene. É possível a leitura? Revista Nonada da UniRitter, v. 08, n. 08, p. 195-203, 2005.

\section{COMO CITAR ESSE ARTIGO}

DE AZEVEDO, Tânia Maris. Aprendizagem da compreensão leitora: uma proposta de transposição didática da Teoria da Polifonia e da Teoria dos Blocos Semânticos. Signo, Santa Cruz do Sul, v. 44, n. 80, jul. 2019. ISSN 1982-2014. Disponível em: <https://online.unisc.br/seer/index.php/signo/article/view/13596>. Acesso em: doi: https://doi.org/10.17058/signo.v44i80.13596. 